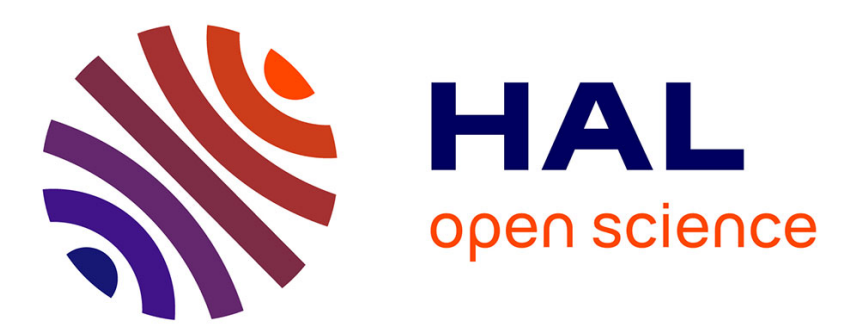

\title{
Cell division, endoreduplication and expansion processes: setting the cell and organ control into an integrated model of tomato fruit development
}

\author{
Valentina Baldazzi, Michel Génard, Nadia Bertin
}

\section{> To cite this version:}

Valentina Baldazzi, Michel Génard, Nadia Bertin. Cell division, endoreduplication and expansion processes: setting the cell and organ control into an integrated model of tomato fruit development. Acta Horticulturae, 2017, 1182, pp.257 - 264. 10.17660/ActaHortic.2017.1182.31 . hal-01661920

\author{
HAL Id: hal-01661920 \\ https://hal.inria.fr/hal-01661920
}

Submitted on 8 Jan 2018

HAL is a multi-disciplinary open access archive for the deposit and dissemination of scientific research documents, whether they are published or not. The documents may come from teaching and research institutions in France or abroad, or from public or private research centers.
L'archive ouverte pluridisciplinaire HAL, est destinée au dépôt et à la diffusion de documents scientifiques de niveau recherche, publiés ou non, émanant des établissements d'enseignement et de recherche français ou étrangers, des laboratoires publics ou privés. 


\title{
Cell division, endoreduplication and expansion processes: setting the cell and organ control into an integrated model of tomato fruit development
}

Valentina Baldazzi, Michel Génard, Nadia Bertin

PSH, INRA, 84941 Avignon, France

\begin{abstract}
The development of a new organ is the result of coordinated events of cell division and expansion, in strong interaction with each other. This paper presents an improved version of a tomato model that includes cells division, endoreduplication and expansion processes. The model is used to investigate the interaction among these developmental processes, in the perspective of a new cellular theory. In particular, different control schemes (either cell- or organ-based) are tested and simulation results are compared to observed data. The model shows that a pure cell-based control fails to reproduce the observed cell size distribution, and an organ-based control is needed in order to get realistic cell and fruit sizes. The model also supports the role of endoreduplication as an important modulator of the cell expansion potential.
\end{abstract}

Keywords: division, expansion, endoreduplication, development, tomato, multi-scale

\section{INTRODUCTION}

The development of a new organ is the result of coordinated events among which cell division and expansion. Fruit growth starts immediately after bloom with intensive cell division. As development proceeds, the proliferative activity of cells progressively slows down giving way to a phase of pure cell enlargement during fruit growth and ripening. In many species, including tomato, the transition from cell division to expansion phases is accompanied by repeated DNA duplications without mitosis, a process called endoreduplication. The exact role of endoreduplication is still unclear, but a strong correlation between cell ploidy (i.e number of DNA copies) and final cell size has been observed in different species (Melaragno and Coleman, 1993; Lee et al., 2004; Bertin, 2005; 
Rewers et al., 2009), suggesting a role of endoreduplication into the control of organ growth (Breuer et al., 2010; Chevalier et al., 2011)

Modeling the way cell division, endoreduplication and expansion processes interact is crucial to understand the emergence of specific morphological traits (fruit size, weight, shape and texture) and their dependence on environmental factors. Historically, a big debate has opposed two contrasting views, the cellular theory vs the organismal, that set the control of organ growth at the level of the individual cell or of the whole tissue, respectively (Beemster et al., 2003; John and Qi, 2008; Harashima and Schnittger, 2010; ). A consensus view, the neo-cellular theory, has emerged. Although individual cells are the units of plant morphology, their behavior (division, expansion) is not autonomous, but coordinated at the organ level by cell-to-cell communication mechanisms, thus creating an effective interaction between cellular and whole-organ control (Beemster et al., 2003).

A first integrated model of tomato fruit was recently developed which explicitly accounts for the early phase of fruit development, coupling cell proliferation and expansion phases (Baldazzi et al., 2012, 2013). Here, an improved version of this model, that includes cell endoreduplication and the possible effect of the ploidy level onto the cell expansion potential, is proposed. The model is used to investigate the interaction among cell division, endoreduplication and expansion processes, in the perspective of the neo-cellular theory. In particular, different control schemes (either cell- or organ-controlled) are tested by means of specific model parameters and simulation results are compared to observed data. The model shows that a pure cell-based control fails to reproduce the observed cell size distribution, and an organ-based control is needed in order to get realistic results.

\section{MATERIALS AND METHODS}

\section{Experimental data}

Observations were collected on cherry (cv. Cervil) tomato genotypes of Solanum lycospersicum L., whose final fresh weight was approximately 6 g. Plants were grown in a greenhouse in the south of France (Avignon) according to standard practices and sampling took place from April to May 2007. Flower buds and fruits were sampled at different time points relative to the time of flower anthesis (full-flower opening). For each inflorescence, half of the fruit pericarps were analysed by flow cytometry and the other half were used for the determination of cell number. The number of pericarp cells was measured after tissue dissociation according to a method adapted from that of Bünger-Kibler and Bangerth (1983) and detailed in Bertin et al. (2003). Cell size distribution was obtained by measuring the 
smallest and largest radius and the 2D-surface of dissociated cells using Image (Schneider et al., 2012). About 20 to 25 cells per fruit were measured. The ploidy was measured in the pericarp tissue after isolation, as described in Bertin et al. (2007). The average value of three measurements per fruit (when allowed for by the fruit's size), was included in the analysis, for a total of 73 observations distributed over fruit development.

Experimental results are shown in Figure 1. At maturity, the observed cell size distribution spans almost two orders of magnitude, with cell surface (cross section) ranging from 0.004 to more than $0.1 \mathrm{~mm}^{2}$. The observed log-distribution is quite symmetric with a mean cell size of $0.029 \mathrm{~mm}^{2}$ and a median of $0.22 \mathrm{~mm}^{2}$.

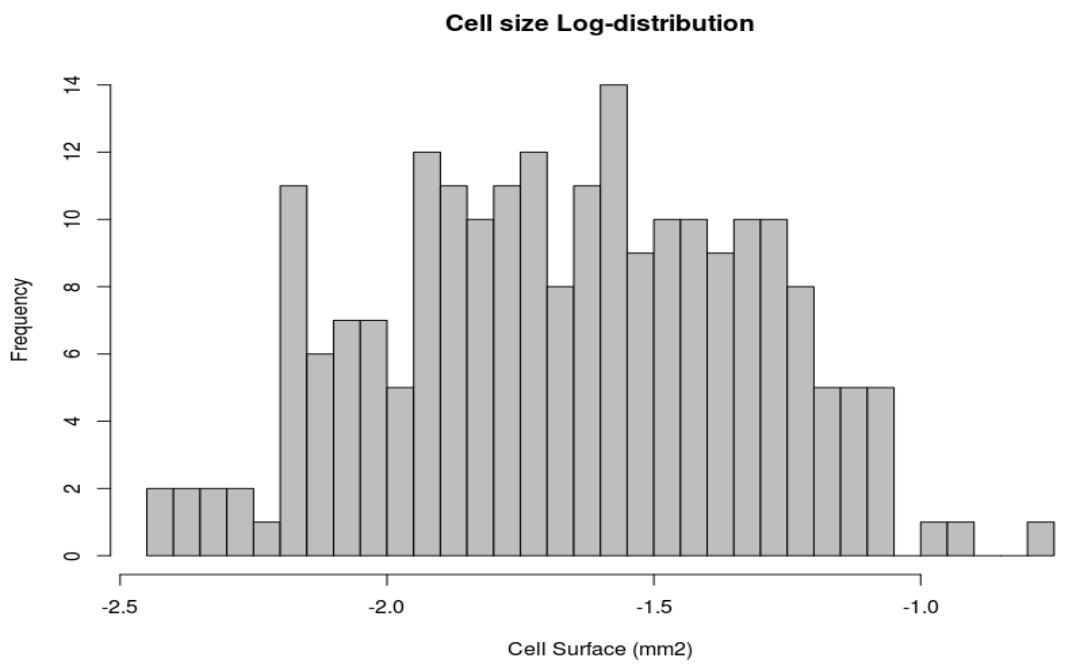

Figure 1: Experimental log-distribution of cell surface at fruit maturity in the Cervil genotype.

\section{Model construction}

A recently developed integrated model of tomato fruit growth explicitly accounts for the early phase of fruit development, thereby coupling cell proliferation and expansion phases (Baldazzi et al., 2013). Here, an improved version of this model that explicitly accounts for the description of DNA endoreduplication, an important mechanism in fruit development, and its possible effects on potential cell expansion, is presented. 


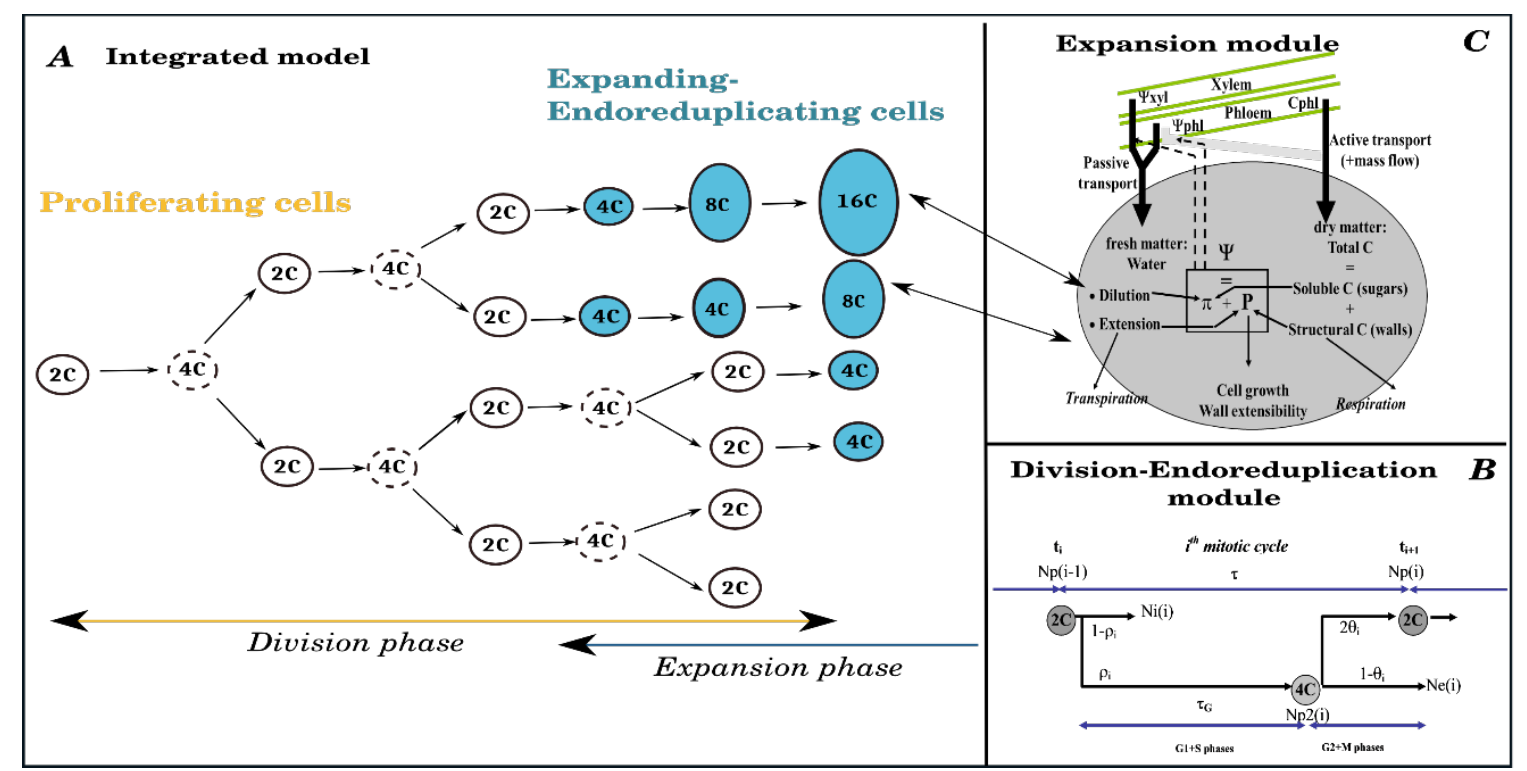

Fig. 2: Panel A: Scheme of the integrated model. The fruit is described as a collection of cell populations, each one having a specific age, ploidy level and volume. It is assumes that the onset of endoreduplication coincides with the beginning of the expansion phase, i.e. expanding cells are endoreduplicating.. Panel $B$. The number of dividing and expanding_endoreduplicating cells is predicted by the division-endoreduplication module, assuming a progressive decline of cells' proliferating activity. Panel $C$ : Expanding cells grow according to the expansion module which provides a biophysical description of the main processes involved in carbon and water accumulation by the cell.

\section{Cell division and endoreduplication module}

A deterministic model is used to predict cell proliferation and cell polyploidization in the tomato fruit pericarp (Bertin et al., 2007) from pre-anthesis to fruit maturation. The model considers a succession of regular division steps together with a progressive decline of the proliferative activity. In each mitotic cycle of duration $\tau$, the proportion of cells proceeding through division depends on a constant parameter $\rho$ and on the progressive decline of the proliferating capacity $\theta$. (Fig $2, \mathrm{~B}$ ). The non-dividing cells may either stop the reduplication fully, or switch to repeated syntheses of DNA without cell division, resulting in cell endoreduplication. A single constant parameter $\sigma$ describes the proportion of cells that moves from one to the next class of DNA content after each lapse of time $\tau_{\mathrm{E}}$, considered to be the minimum time required for an endocycle. All these parameters are considered to be independent from environmental conditions for the time being.

\section{Cell expansion module}

The biophysics of cells expansion is included according to the model by Fishman and Génard (1998), originally developed for peach fruit and then successfully adapted to other species, including tomato (Liu et al., 2007). Accordingly, cell expansion is described by iteratively solving the Lockhart equation relating the rate of volume increase to the cell's 
internal pressure and cell's mechanical properties (Lockhart, 1965). Flows of water and solutes across the membrane are described by thermodynamic equations. As detailed in the original models, the total uptake of carbon from phloem is the sum of contributions from mass flow through plasmodesmata, passive diffusion and active carbon transport across the cell membrane (Fig $2 \mathrm{C}$ ). The relative importance of each transport process may vary along fruit developmental stages, depending on specific developmental control rules

\section{Integrated cell division-endoreduplication-expansion model}

The integrated model starts at the end of the division-only phase, when the proliferative activity of the cells declines and the expansion phase begins (Baldazzi et al., 2013). The fruit is described as a collection of cell populations, each one having a specific age, ploidy level and volume. It is assumes that the onset of endoreduplication coincides with the beginning of the expansion phase, i.e. expanding cells are endoreduplicating (Fig. 2 A). The number, age (initiation date) and physiological state (proliferating or endoreduplicating-expanding cells) of each population is predicted by the cell divisionendoreduplication model (Fig. 2 A). The initial number of cells is $\mathrm{N}(0)=n$ and the initial mass of the fruit is $\mathrm{V}(0)=n^{*} m 0=n^{*}(w 0+s 0)$, where $w 0$ and $s 0$ are initial cell water and dry mass, respectively. At any time, cells leaving the proliferative phase start to grow, from an initial mass $2^{*} \mathrm{mO}$ and a ploidy level of $4 \mathrm{C}$, according to the expansion model and current environmental conditions.

In the integrated model, as in the orginal expansion module, a number of timedependent functions account for developmental regulation of different growth processes (Baldazzi et al. 2013). Two characteristic time-scales are recognizable in the model: the cell age, i.e. the time spent since an individual cell has left the proliferative phase, and fruit age i.e. the time spent since the first expanding cells have appeared ( 8 days before anthesis, for the considered genotype). Depending on the settings of the corresponding time-dependent functions, different cellular processes may be put under the control of the cell or organ levels, allowing for an in silico exploration of alternative control hypotheses in the perspective of the cellular and organismal theories. Moreover, a direct effect of the ploidy level on cell expansion may be tested according to biological hypotheses ( Sugimoto-Shirasu and Roberts, 2003; Chevalier et al., 2011; Edgar et al., 2014;).

\section{RESULTS AND DISCUSSION}

\section{A simple cell-based control scheme leads to unrealistic cell size distribution}

In first instance, the case of a simple cell-based control was considered. Two cells with the same age, even if initiated at different fruit developmental stages, will behave 
identically in what concerns carbon metabolism, transport and wall mechanical properties. For sake of simplicity, a constant non-limiting environment, i.e. constant temperature, humidity and plant status (water potential and sap sugar concentration), and no effect of ploidy level on cell expansion properties was considered.
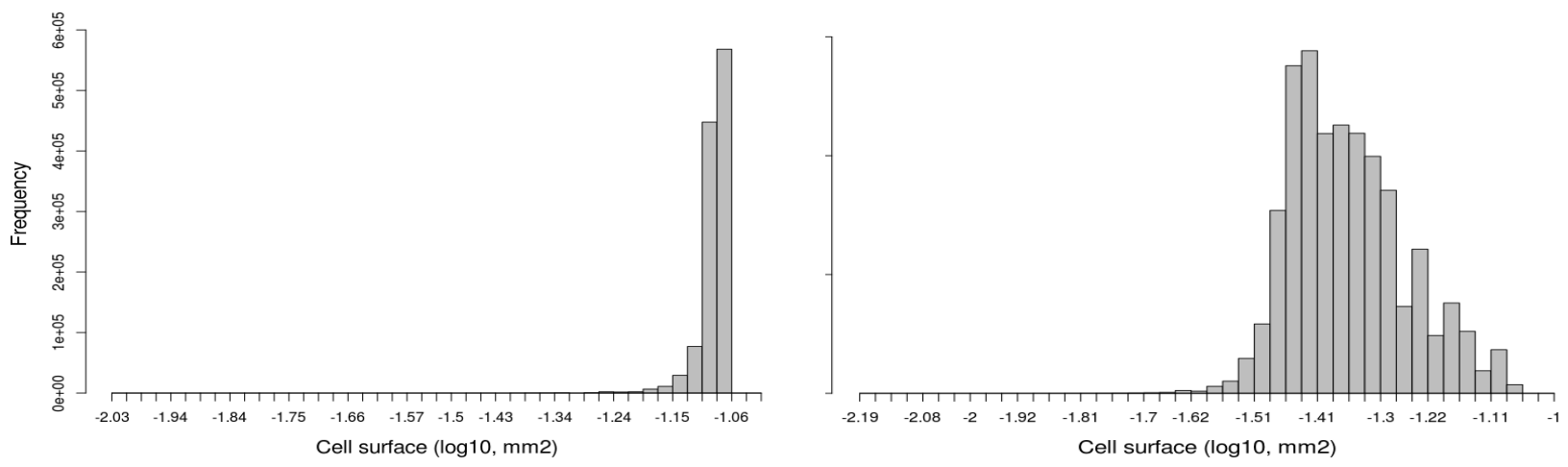

Figure 3: Left: Simulated cell size distribution at fruit maturity under a cell-based control scheme. Right: Simulated cell size distribution at fruit maturity assuming an organ-based control on carbon symplastic transport. The possible effect of DNA ploidy level on cell growth was not considered here.

The resulting fruit is composed of big cells, with a mean cross surface around 0.06 $\mathrm{mm}^{2}$. Cell size distribution appears left-queued and a lot narrower than in real data (Fig. 1), most of the cell surfaces being localized within a $0.02 \mathrm{~mm}^{2}$ range (Fig. 3, Left). In this case, variability is due only to age differences among cells.

\section{Effect of organ-control on cell size distribution}

The addition of an organ-control mechanism introduces an additional source of variability among cells. In this case, two cells of the same age which were initiated at different fruit stages will not behave identically, resulting in different expansion capabilities and resulting growth dynamics (Baldazzi et al. 2013). Several schemes of organ-based control have been tested in silico, based on available literature and common sense.

The first weeks of tomato fruit development are accompanied by rapid changes in cuticle synthesis and composition. In particular, a reduced wax layer in young stages results in a high skin conductance and increased water loss by transpiration (Lee, 1990). Setting conductance as a function of fruit age, however, leads to almost no change in the shape of the cell size distribution, consistently with the reduced magnitude of the transpiration flux with respect to other cell fluxes (Baldazzi et al., 2013).

In tobacco leaves, intercellular movement of macromolecules across plasmodesmata has been shown to be affected by leaf age and physiological conditions (Crawford and 
Zambryski, 2001; Zambryski, 2004). By setting the corresponding model parameter as a function of organ age, cell size distribution gets larger, spanning almost 1.5 orders of magnitude, and more symmetric (Fig. 3, Right). Maximum cell size is equivalent to the one reached under a cell-based control, suggesting sub-optimal conditions for cell expansion.

Cell wall mechanics are known to be largely affected by cell developmental stage and environmental conditions (Bargel and Neinhuis, 2005; Cosgrove, 2005; Wolf et al., 2012;Braidwood et al., 2014). In particular, the expression of specific expansins has been associated with stages of rapid fruit growth and fruit softening during maturation, suggesting a possible connection with the organ scale (Brummell et al., 1999; Catala et al., 2000). The in silico test with the model leads however to unrealistic results. Changes in cell mechanical parameters (wall plasticity) as a function of fruit age indeed spread the predicted cells size distribution, but result in an extremely high internal pressure and an unnatural water and sugar backflow from fruit cells to the plant. As a consequence, very small cells appear on the left side of the cell size distribution and outside of the observed variability range at fruit maturity (Fig. 1).

\section{Endoreduplication and cell growth: possible interactions}

A high level of ploidy has been often associated with an increased cell size, suggesting a role for endoreduplication in cell growth. Literature points to the ploidy level determining the maximum potential cell size (Fanwoua et al., 2013) that can be attained or not, depending on internal (hormones/development) and external (environmental) factors (Breuer et al., 2010; Chevalier et al., 2011; De Veylder et al., 2011). Endoreduplication has indeed been associated with an elevated protein synthesis and transcriptional activity (Chevalier et al., 2014), suggesting a general activation of the nuclear and metabolic machinery of the cell to sustain cell growth. Following these insights, it was decided to add the effect of endoreduplication on cell expansion as a ploidy-dependent maximal import rate for carbon uptake. Results are shown in Figure 4. As expected, a high ploidy level resulted in a larger cell size, although variability was present due to asynchronous endoreduplication patterns among cells (Fig. 4, Right). Thanks to the contribution of endoreduplication, cell size distribution becomes larger and reaches the observed variability range. With respect to the real data (Fig. 1), the predicted cell size distribution seems a little bit more right-queued, but experimental methods may be limited in their sampling capacity when individuals are scarce, as in the case of highly endoreduplicated cells. 

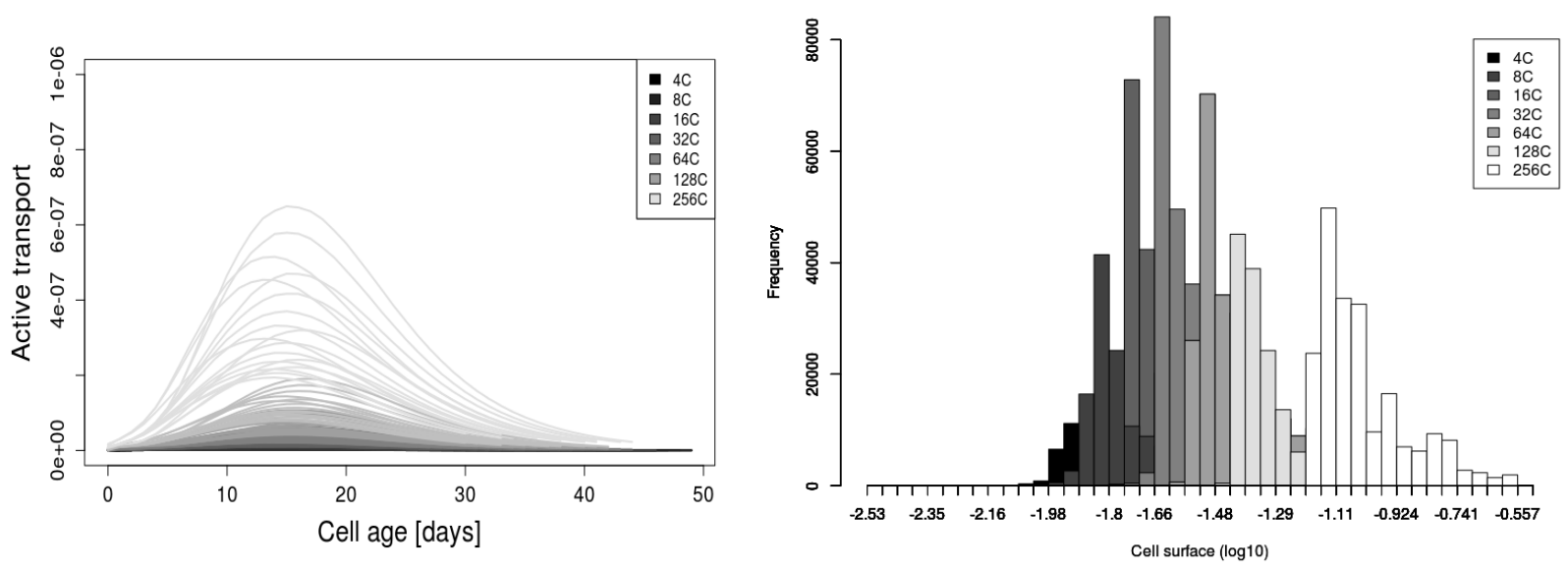

Figure 4:Left:Carbon import rate by active transport as a function of the cell ploidy level. Final cells ploidy is indicated on a greyscale: dark greys correspond to low ploidy levels whereas white curves correspond to highly poliploidy cells, as indicated in the inset. High endoreduplicated cells have a larger C import rate. Right: Resulting simulated cell size distribution at maturity. Higher endoreduplicated cells are generally larger, although variability is observed due to asynchronous endoreduplication patterns among cells.

\section{CONCLUSIONS}

The present paper presents an improved version of an integrated cell divisionexpansion model that explicitly accounts for DNA endoreduplication, an important mechanism in tomato fruit development. The model is used to investigate the interaction among cell division, endoreduplication and expansion processes, and their degree of control by cell- or organ-dependent factors, in the perspective of the neo-cellular theory (Beemster et al., 2003). Model simulations show that a pure cellular control is unable to reproduce the observed cell size distribution in terms of both average cell size and the variability range. The model thus supports the need for an organ-based control of cellular processes, suggesting the modulation of symplastic carbon transport as a good candidate control point. The model also supports the role of endoreduplication as an important modulator of cell expansion potential. A refined model with a ploidy effect on carbon uptake rate, capable of reproducing the observed cell size distribution patterns in tomato fruits is thus proposed.

It is important to note that other mechanisms not considered here, can contribute to the observed cell size variability, among which the intrinsic stochasticity of cell cycle and division processes ( Prusinkiewicz, 2011; De Smet and Beeckman, 2011;Osella et al., 2014), as well as their dependence on environmental factors and intrinsic fluctuations (Halter et al., 2009; Roeder et al., 2010). In perspective, the model could be used to evaluate the percentage of variability associated with these mechanisms, in an attempt to better elucidate 
the role of individual processes in the control of organ development.

\section{Literature cited}

Baldazzi, V., Bertin, N., de Jong, H., and Génard, M. (2012). Towards multiscale plant models: integrating cellular networks. Trends Plant Sci. 17, 728-736.

Baldazzi, V., Pinet, A., Vercambre, G., Bénard, C., Biais, B., and Génard, M. (2013). In-silico analysis of water and carbon relations under stress conditions. A multi-scale perspective centered on fruit. Front. Plant Sci. 4, 495.

Bargel, H., and Neinhuis, C. (2005). Tomato (Lycopersicon esculentum Mill.) fruit growth and ripening as related to the biomechanical properties of fruit skin and isolated cuticle. J. Exp. Bot. 56, 1049-1060.

Beemster, G.T.S., Fiorani, F., and Inzé, D. (2003). Cell cycle: the key to plant growth control? Trends Plant Sci. 8, 154-158.

Bertin, N. , Génard M. Fishman S. (2003). A model for an early stage of tomato fruit development: cell multiplication and cessation of the cell proliferative activity. Ann. Bot. 92, 65-72

Bertin, N. (2005). Analysis of the tomato fruit growth response to temperature and plant fruit load in relation to cell division, cell expansion and DNA endoreduplication. Ann. Bot. 95, 439-447.

Bertin, N., Lecomte, A., Brunel, B., Fishman, S., and Génard, M. (2007). A model describing cell polyploidization in tissues of growing fruit as related to cessation of cell proliferation. J. Exp. Bot. 58, 1903-1913.

Braidwood, L., Breuer, C., and Sugimoto, K. (2014). My body is a cage: Mechanisms and modulation of plant cell growth. New Phytol. 201, 388-402.

Breuer, C., Ishida, T., and Sugimoto, K. (2010). Developmental control of endocycles and cell growth in plants. Curr. Opin. Plant Biol. 13, 654-660.

Brummell, D.A., Harpster, M.H., Civello, P.M., Palys, J.M., Bennett, A.B., and Dunsmuir, P. (1999). Modification of Expansin Protein Abundance in Tomato Fruit Alters Softening and Cell Wall Polymer Metabolism during Ripening. Plant Cell 11, 2203-2216.

Bünger-Kibler S, Bangerth F. (1983). Relationship between cell number, cell size and fruit size of seeded fruits of tomato (Lycopersicon esculentum Mill.), and those induced partheno-carpically by the application of plant growth regulators. Plant Growth Regulation 1, 143-154

Catala, C., Rose, J.K.C., and Bennett, A.B. (2000). Auxin-Regulated Genes Encoding Cell Wall-Modifying Proteins Are Expressed during Early Tomato Fruit Growth. Plant Physiol. 122, 527-534.

Chevalier, C., Nafati, M., Mathieu-Rivet, E., Bourdon, M., Frangne, N., Cheniclet, C., Renaudin, J.-P., Gévaudant, F., and Hernould, M. (2011). Elucidating the functional role of endoreduplication in tomato fruit development. Ann. Bot. 107, 1159-1169.

Chevalier, C., Bourdon, M., Pirrello, J., Cheniclet C., Gevaudant F. and Frangne, N. (2014). Endoreduplication and fruit growth in tomato: Evidence in favour of the karyoplasmic ratio theory. J. Exp. Bot. 65, 2731-2746.

Cosgrove, D.J. (2005). Growth of the plant cell wall. Nat. Rev. Mol. Cell Biol. 6, 850-861.

Crawford, K.M., and Zambryski, P.C. (2001). Non-targeted and targeted protein movement through plasmodesmata in leaves in different developmental and physiological states. Plant Physiol. 125, 1802-1812.

De Smet, I., and Beeckman, T. (2011). Asymmetric cell division in land plants and algae: the driving force for differentiation. Nat. Rev. Mol. Cell Biol. 12, 177-188. 
De Veylder, L., Larkin, J.C., and Schnittger, A. (2011). Molecular control and function of endoreplication in development and physiology. Trends Plant Sci. 16, 624-634.

Edgar, B.A., Zielke, N., and Gutierrez, C. (2014). Endocycles: a recurrent evolutionary innovation for post-mitotic cell growth. Nat. Rev. Mol. Cell Biol. 15, 197-210.

Fanwoua, J., de Visser, P.H.B., Heuvelink, E., Yin, X., Struik, P.C., and Marcelis, L.F.M. (2013). A dynamic model of tomato fruit growth integrating cell division, cell growth and endoreduplication. Funct. Plant Biol. 40, 1098.

Fishman, S., and Génard, M. (1998). A biophysical model of fruit growth: simulation of seasonal and diurnal dynamics of mass. Plant Cell Env. 21, 739-752.

Halter, M., Elliott, J.T., Hubbard, J.B., Tona, A., and Plant, A.L. (2009). Cell volume distributions reveal cell growth rates and division times. J. Theor. Biol. 257, 124-130.

Harashima, H., and Schnittger, A. (2010). The integration of cell division, growth and differentiation. Curr. Opin. Plant Biol. 13, 66-74.

John, P.C.L., and Qi, R. (2008). Cell division and endoreduplication: doubtful engines of vegetative growth. Trends Plant Sci. 13, 121-127.

Lee, D.R. (1990). A unidirectional water flux model of fruit growth. Can J Bot 68, 1286-1290.

Lee, H.-C., Chiou, D.-W., Chen, W.-H., Markhart, A.H., Chen, Y.-H., and Lin, T.-Y. (2004). Dynamics of cell growth and endoreduplication during orchid flower development. Plant Sci. 166, 659-667.

Liu, H.-F., Génard, M., Guichard, S., and Bertin, N. (2007). Model-assisted analysis of tomato fruit growth in relation to carbon and water fluxes. J. Exp. Bot. 58, 3567-3580.

Lockhart, J.A. (1965). An analysis of irreversible plant cell elongation. J. Theor. Biol. 8, 264-275.

Melaragno, J.E., and Coleman, A.W. (1993). Relationship between endopolyploidy and cell size in epidermal tissue of Arabidopsis. Plant Cell 5, 1661-1668.

Osella, M., Nugent, E., and Cosentino Lagomarsino, M. (2014). Concerted control of Escherichia coli cell division. Proc. Natl. Acad. Sci. U. S. A. 111, 4-8.

Prusinkiewicz, P. (2011). Inherent randomness of cell division patterns. Proc. Natl. Acad. Sci. U. S. A. 108, 59335934.

Rewers, M., Sadowski, J., and Sliwinska, E. (2009). Endoreduplication in cucumber (Cucumis sativus) seeds during development, after processing and storage, and during germination. Ann. Appl. Biol. 155, 431-438.

Roeder, A.H.K., Chickarmane, V., Cunha, A., Obara, B., Manjunath, B.S., and Meyerowitz, E.M. (2010). Variability in the control of cell division underlies sepal epidermal patterning in Arabidopsis thaliana. PLoS Biol. 8, e1000367.

Schneider, C. A., Rasband, W. S., and Eliceiri, K. W. (2012). NIH Image to ImageJ: 25 years of image analysis. Nat methods, 9(7), 671-675.

Sugimoto-Shirasu, K., and Roberts, K. (2003). "Big it up": endoreduplication and cell-size control in plants. Curr. Opin. Plant Biol. 6, 544-553.

Wolf, S., Hématy, K., and Höfte, H. (2012). Growth control and cell wall signaling in plants. Annu. Rev. Plant Biol. $63,381-407$.

Zambryski, P. (2004). Cell-to-cell transport of proteins and fluorescent tracers via plasmodesmata during plant development. J. Cell Biol. 164, 165-168. 
